\title{
Perspectives and Policies on ICT in Africa
}

\author{
Jonathan MILLER \\ Trigrammic \\ Hout Bay, South Africa \\ jonmil@icon.co.za
}

"While there has been great value in focusing on the profound digital differences between developed and developing countries, the downside has been a potential and insidious distinction between civilized tool-users and uncivilized non-users. What is missing is a deeper focus on the "true" knowledge needs of particular cultures

and communities, and the relevance of ICT to individual social contexts."

Key words: Information technology, telecommunications, ICT, Internet, policy, digital divide, Africa, development, social norms.

To understand ICT in Africa, one must first understand Africa: a continent comprising fifty-four countries showing extreme diversity, in most cases grinding poverty, high levels of public debt, unhealthy dependence on international donor funding, vast geographic dispersion and low population densities, a multiplicity of languages and very low levels of literacy, and a continent ravaged by HIV/AIDS. Africa is also characterised by political turmoil, endemic warfare, an agrarian society and a generally very weak private sector. In all, Africa comprises $10 \%$ of the world's population but only $1 \%$ of world GDP.

Despite the gloomy picture this paints, there are signs of significant improvements in prospects for the continent. Peace appears to be breaking out, with recent agreements between warring nations and troop withdrawals in the Great Lakes region in particular. There is more evidence of working democracies. In 2002 the moribund and ineffective Organisation of African Unity was replaced by the African Union. The New Partnership for African Development (NEPAD) was launched with great fanfare and, despite 
hitches, seems to be establishing itself as the continent-wide mechanism to build political and economic stability.

While the continent battles with the social and economic circumstances outlined above, it is also caught up in the burgeoning field of telecommunications, the Internet and ICT. International agencies are strongly encouraging African governments to launch themselves into the Knowledge Era and see ICT as an essential component of their economic and social resurgence. One of the outcomes is seen in African leaders' response - the NEPAD programme - which identifies ICT as one of its four pillars and has formed the eAfrica Commission to spearhead ICT activities. Some say ICT is the last hope for Africa to participate effectively in the global economy.

Any discussion of ICT in the developing world inevitably addresses the so-called "digital divide" between the developed and developing world. Definitions vary, but essentially this notion refers to the huge, and widening, gap between developed and developing world as regards availability and cost of computer hardware, software and access to telecommunications facilities, including telephones and the Internet. It also refers to indigenous capabilities to use the telecom infrastructure for socio-economic development. It is argued that the gap will continue to widen - especially in Africa - unless the continent makes heroic efforts.

There are, indeed, innumerable efforts to "narrow the divide" and, as discussed below, some notable successes. The process seems to be taking a long time, however, and many examples of well-meaning efforts have failed dismally. New terms are being invented such as "digital opportunities" and suggestions that there is no such thing as a digital divide, but rather a "development divide." In fact, recently, there have been calls to reconceptualise the Digital Divide in ways that will redirect efforts towards more effective solutions. ${ }^{1}$ We return to this topic later in the chapter, but first we flesh out the top level initiatives designed to better exploit ICT in Africa and discuss some of the outcomes to date.

\section{TOP LEVEL INITIATIVES}

Despite the awesome challenges facing the continent - arguably needing attention before even contemplating a focus on the information society there is an impressive array of policies, programmes, projects designed to apply the benefits of ICT to Africa. Most of those activities originated in 1995 with a key speech by South Africa's then deputy-President Thabo Mbeki to the Brussels G7 Conference on the Information Society, in which he challenged the developed world to engage the developing world on the 
issue of the Information Society. A direct outcome of that intervention was the so-called ISAD (Information Society and Development) Conference that took place in South Africa in 1996, for the first time engaging the developed and developing world in a debate about the information society and development.

Among several resolutions passed and announcements made at ISAD, perhaps the one of most relevance for this chapter was that by the UN Economic Commission for Africa that launched the African Information Society Initiative (AISI). The AISI comprised an action plan "to build Africa's information and communications infrastructure (NICI)."

The action plan calls for

"the elaboration and implementation of national information and communication infrastructure plans involving development of institutional frameworks, human, information and technological resources in all African countries and the pursuit of priority strategies, programmes and projects which can assist in the sustainable build up of an information society in African countries."

In the ensuing years many African countries embarked upon ICT policy and planning processes. As of 2002 some twenty-seven countries claimed to be at various stages in building national ICT infrastructures. For example:

In Mozambique lengthy consultative processes since the mid-90s led to the Government adopting an ICT policy in $2000{ }^{2}$ There are six priority areas: Education, Health (with a priority on HIV/AIDS), Human Resource Development, Infrastructure, Access and Governance. In place is an ICT Policy Commission in the Prime Minister's office, but to date there is little evidence of tangible outcomes.

- Tanzania has also seen the need to develop a policy that addresses the ICT Sector as a whole. Unusual is the emergence of a strong forum of businessmen, government employees, academics and donor organisations called "eThinkTank," a group that engages in vigorous debate on ICT matters via an electronic list server. In October 2001 the group held a public forum where it tabled Terms of Reference for the development of an ICT policy. This triggered the formation of an official government group to carry the ICT policy process forward. The Tanzanian Government adopted the proposed policy in 2003 and is proceeding to form a top level implementation body.

- Rwanda first engaged in ICT policy formation in 1998. By 2001 there was a report presented to the President, entitled: An Integrated ICT-led Socio-Economic Development Policy and Plan for Rwanda $2001-2005$. The document suggests a budget of US\$ 500 million together with broad timeframes and responsible government departments. To date, 
however, there has also been little tangible action, possibly since there have been delays in constituting the planned implementing agency.

There was an important opportunity to reflect on progress in ICT in Africa at the first African Development Forum in Addis Ababa in 1999. The overall theme was Globalisation and the Information Economy: Challenges and Opportunities for Africa. Four priority sub-themes emerged:

- Creating the Enabling Policy Environment,

- ICT, Youth and Education,

- ICT and Health, and

- Electronic Commerce.

Subsequently the ECA AISI group issued a "Common Position for Africa's Digital Inclusion" elaborating on these recommended sub-themes, which now enjoys wide acceptance. The eAfrica Commission mentioned above is the natural body to carry forward the recommendations, but remains at an early stage of development.

This is not the place to offer a comprehensive analysis of all the elements of the various policies in place or in process, but it can be stated that most of the real activity in ICT policy making throughout Africa remains at the level of formation of national ICT commissions and central implementation agencies, establishment of telecom regulators and moves towards telecommunications liberalisation and privatisation. Most countries have yet to translate their policy proposals into action on the ground.

In addition to the initiatives described above, there are many others involving bilateral and multilateral organisations, the donor community and the countries themselves. The Appendix lists several with weblinks. One of the most popular projects receiving funding from such entities nowadays is the so-called "eReadiness" assessment. Many African countries have been subject to such assessments - sometimes more than once - where consultants carry out quantitative assessments of telecom infrastructure, ICT-related education and training, diffusion of ICT into government, business and civil society in general, and policy and regulatory issues. The crucial question is to what extent the numerous top-level, well-funded projects and programmes have helped Africa. Certainly, despite the AISI and $\mathrm{ADF}$ ' 99 , much needs to be done in order to achieve higher order goals, such as application of ICT to health and education, promotion of eCommerce and eGovernment, let alone achievement of the overarching notion of an Information Society. 


\section{ICT SUPPLY AND DEMAND}

\section{Supply}

There is abundant evidence that the supply of telephones and the Internet in Africa is growing at a rapid rate. Any assessment, however, has to be seen in light of aspects such as:

- The extremely low base from which the continent is developing. For instance, while all are aware that the number of telephones per hundred people in Africa is far lower than that for typical developed countries, it is salutary that the ratio of perhaps $1: 100$ persons is five times worse even than the average "low income" country. The number of Internet users is estimated at between 1:250 and 1:400 persons, compared with the world average of 1:13 and that for North America of 1:2.

- Disparities between countries. Overall averages for Africa conceal major differences within Africa, whether between capital cities and the rest of the country, or between the better endowed countries like South Africa, Egypt, Morocco and Nigeria, and the least well-endowed like Eritrea, Somalia, Central African Republic, etc.

- The importance of the overall context for ICT equipment and applications. The growth of ICT is severely hampered by poor and fluctuating electricity supply in most of Africa; very unreliable and costly transportation via road, rail and air links; time-consuming and unpredictable procedures at border posts; tax regimes that consider computers to be luxury goods; very low levels of education and literacy and the growing brain-drain of those that do gain superior qualifications.

Nonetheless there are notable advances in the availability of information and telecommunications technologies in Africa. While fixed line telephony is minimal and growing only at about $6 \%$ per annum in real terms (i.e., taking into account population growth), there has been a veritable explosion in mobile telephony. There are now some 100 GSM networks in 48 African countries providing service to 14 million customers (plus a further 10 million in South Africa). This subscriber base is well in excess of fixed lines and is made even more surprising by the high cost of mobile calls: 20-40 US cents a minute. Such rapid growth underlines a fundamental demand, supported by an open competitive market for mobile telephony characteristic of virtually all African countries, and the highly successful pre-paid business model that attracts well over $80 \%$ of all subscribers. ${ }^{3}$

Internet growth is rapid as well, although outside of North and South Africa, there are currently perhaps only two million Internet users. On the positive side the Internet market is generally competitive with some 560 Internet Service Providers on the continent serving individuals, business and 
government via dialup and leased lines. International bandwidth is growing rapidly (e.g., 700-1500 Mbps from 2001 to 2002), but not as rapidly as the world as a whole (174\%) and Latin America in particular (479\%). Again, while prices for international connectivity are declining and many African countries are rolling out Points of Presence (POPs) in secondary towns, and a price structure that permits all Internet calls at local prices, the cost of Internet access remains relatively very high. Most access via the public telephone system is charged per minute (which is known to severely inhibit usage) and typical monthly Internet subscriptions run at US\$60. Given relative purchasing power, this makes Internet access at least ten times more expensive than in a typical developed country.

Significant in Africa is the prevalence of public access points for telecommunications and in particular the Internet. While early models focused on so-called multi-purpose telecentres that might offer business, training, telephony, computing and Internet facilities, the somewhat smaller and simpler "cybercafés" offering Internet access and perhaps some secretarial services, have become very popular ${ }^{4}$. For instance it is estimated that there are several hundred such cybercafés in Tanzania alone. While $80 \%+$ are in the main city of Dar es Salaam, there is a growing incidence of such facilities in secondary towns, as telecom infrastructure spreads into the regions and local districts. Other models include the several thousand phoneshops in Senegal. Overall, given the relatively high cost of a domestic telephone and Internet service in Africa (as well as long waiting lists for service and subsequent maintenance and service problems), different models of public access points such as cybercafés and phoneshops, and public access points in schools, police stations, clinics, hotels etc. can be expected to proliferate over the coming years.

Related to this phenomenon is that of Internet Telephony, or "Voice over IP." VOIP enables voice communications by digitising analogue signals and transmitting the resultant data packets using the Internet protocol. While in many cases the quality of the voice transmission remains poorer than the analogue equivalent, this is changing. Indeed many public telephone companies are now contracting with backbone providers to transmit their own international traffic using VOIP. The use of VOIP by individual Internet users, ISPs, mobile operators etc., is, however, illegal in most countries of the world. This because it enables anyone with Internet access to bypass the licensed telephony operators (often still a government monopoly), depriving them of revenue in the process. This in turn challenges the typical country telecom policy and regulatory environment, especially in Africa. On the other hand Africa is characterised by its large Diaspora. Many families have members overseas with whom they wish to stay in touch. VOIP avoids the - typically extremely high - international 
telephone costs (which subsidise local calls and rentals) that such contact would imply. Some say the business model for cybercafés relies heavily on VOIP, which is very difficult to police. Thus we see more and more country governments and telecomm regulators tackling the issue and essentially preparing the way to legalise VOIP.

Outside a few countries like South Africa, there are virtually no computers other than PCs. Estimates of PCs vary from 1:100 to 1:500 persons. Most of those will be found in private businesses as opposed to government offices or homes and will most likely be running the Windows operating system and applications software. The major PC suppliers generally have a presence in African countries via agents and distributors rather than country offices. For this reason among others, technicians are in very short supply and support and maintenance is very difficult. Where PCs are present in larger firms and government departments they are much less likely to be linked in a LAN than in a developed context.

ICT technical and professional training and education is minimal in Africa, but is attracting a lot of international interest lately. Donors are funding training institutes and programmes for computer technicians and to impart entry level computing skills, and tertiary institutions, with and without funding support, are launching and growing advanced telecom and ICT professional training programmes. ${ }^{5}$ The numbers of graduates of most of these programmes remains very small, however, and there is widespread concern that many of those who graduate join the brain-drain. Clearly this inhibits the demand for, and application of, ICT in Africa.

\section{Demand}

As mentioned previously in this chapter, at the African Development Forum (ADF) 99, education, health and eCommerce were identified as key application areas for ICT. To date, however, there is but a smattering of such activity in Africa.

- Despite the many offers of donor funding and awarded contracts, access to computers and the Internet in schools and universities remains confined to a tiny proportion of African institutions. The presence of active SchoolNet NGOs in several countries and the recent launch of SchoolNet Africa to coordinate those initiatives may augur well for more rapid incorporation of computers and the Internet into school curricula. To date, however, there is certainly no evidence of a changing culture of learning, for instance, applying distance learning protocols, This is not surprising, given the paucity of other facilities such as teachers, electricity, water and classrooms that characterises education in Africa. 
- The health sector also suffers under the burden of a desperate lack of medical professionals, drugs, consumables and medical facilities - all in the face of the catastrophic rise in HIV/AIDS and other diseases like malaria. While there are long-standing electronic communications networks such as HealthNet linking medical professionals in Africa, and a rapidly increasing emphasis on the use of the Internet and the Web to support health initiatives, the potential benefits of approaches such as telemedicine have yet to be tapped.

- Electronic commerce too is at a nascent stage. There are some (and a growing number) of examples of African entrepreneurs using eCommerce facilities, but in almost all African countries, fundamental aspects such as cash-based economies, primitive banking systems, very poor and expensive logistics and concerns about corruption severely inhibit this sector.

A brief review of recent content of a popular electronic newsletter on ICT in Africa reveals an interesting collection of real applications of ICT in Africa. There are agricultural applications including web sites offering current weather conditions, research data and information relevant to local fishing companies, as well as access to produce prices via SMS messages on mobile phones. There are attempts to provide guidance for starting up small and micro enterprises, enabling bill payments over mobile phones and smart cards to pay for usage in Internet cafés. There are references to healthcare applications, use of ICT in electoral administration, and provision of information to help teachers, ${ }^{6}$ but such examples are few and far between. Noticeable is the absence of applications, for instance, to provide language translation, innovative user interfaces to allow people with low levels of literacy to access useful information, implementation of wireless application reaching into remote rural areas, etc.

\section{Towards an African Information Society}

The previous sections of this chapter offer abundant evidence of top level commitments to building ICT infrastructure in African countries, applying ICT to directly address profound problems such as the burden of disease, realising the benefits of ICT for education and assisting African entrepreneurs to enter the global marketplace. Does this mean that Africa has become an Information Society? Certainly not. Is ICT being appropriately applied to serve the developmental needs of the poorest countries? Hardly. There is a concern that the notion of ICT for development has assumed a narrow and possibly inappropriate meaning. It may simply be encouraging all countries to emulate the patterns of use of ICT in industrialised countries, "catching up" by following in their footsteps 
of technology and socio-economic innovation and thereby avoid marginalisation in a global economy.

As was briefly presented in the previous section, the benefits of ICT are starting to be seen in the growing number of ICT applications in key sectors of African economies. However, this is only part of the story. The thrust of almost all top-level interventions by government and international donors and today's application of ICT in developing countries is largely in the hands of the minorities - whether in the public or private sector - who find its global symbolic and material value meaningful in their way of living and therefore are willing and able to acquire the skills and attitudes required to exploit its potential. This bias comes out in most discussions of the so-called Digital Divide, where the emphasis remains on the supply side: install sufficient telephone lines (or mobile phones), provide sufficient computers, make the Internet widely available, and the rest will follow. While there has been great value in focusing on the profound digital differences between developed and developing countries, the downside has been a potential and insidious distinction between civilized tool-users and uncivilized non-users.

What is missing is a deeper focus on the "true" knowledge needs of particular cultures and communities, and the relevance of ICT to individual social contexts. This aspect is receiving more academic and practitioner attention nowadays with a shift in perspective from the digital divide to "ICT for social inclusion." Here social inclusion may be achieved when "individuals, families, and communities are able to fully participate in society and control their own destinies, taking into account a variety of factors related to economic resources, employment, health, education, housing, recreation, culture, and civic engagement. ${ }^{7}$ The criteria to achieve such a condition are much broader than simply making computers and the Internet available. Warschauer proposes four areas of attention useful to frame the enquiry. These are listed below with brief commentary on the general situation in Africa.

(1) Physical Resources, encompassing access to computers and telecommunication connections. As discussed earlier in this chapter, this has been the area of most activity in ICT in Africa and its impact cannot be overstated. The last few years have seen a profound upgrading of basic telephony, an explosion in mobile services, and rapidly growing access to the Internet. There can be little doubt that this has had, and is having, a beneficial impact on the economies of many African countries. It is also noteworthy that despite an order of magnitude difference in price between fixed line and mobile telephony in most African countries, the local populace appears to have a great propensity to consume mobile minutes. But still missing is the provision of voice and data access in most secondary 
towns and villages throughout Africa, thus forcing large numbers of rural inhabitants to travel long distances to exchange messages.

(2) Digital Resources. This addresses the provision of digital material online. If we view such resources as necessary for commercial activity and streamlining the provision of government services then we need to consider the widespread transfer of tacit knowledge into information systems, giving countries access to new process technologies and products developed in the industrialised countries, both rapidly and at low cost. This is happening to a degree and certainly the focus on eGovernment is growing apace.

But are Africans developing their own ICT materials? To what extent is access to ICT tailored to uniquely African social contexts? How relevant is ICT to the way Africans live their lives? Are Africans using computing devices and connectivity to engage in meaningful social practices, or simply to meet imported visions of modernity stressing decontextualised, formal knowledge as opposed to local formal and tacit knowledge? In the end, how relevant is ICT to the way Africans live their lives? There is very little evidence of appropriate user interfaces, web pages in local languages, etc. that would allow the broad mass of urban and rural populations to use ICT in ways meaningful to themselves.

(3) Human Resources, dealing with issues such as literacy and education (including the particular types of literacy practices that are required for computer use and online communication). Does ICT enable Africans to have "mastery over the processes by means of which culturally significant information is coded?" Is ICT providing access to information sources and communications media that are useful for learning and innovation? Despite valiant attempts to introduce computers and connectivity to schools, even in South Africa, the most connected of African societies, school computer laboratories and facilities for distance learning and training in information literacy are almost non-existent. There is much talk about cybercafés as valuable entities for public access. While true, again the incidence is minimal and the uses to which such facilities are put have more to do with western models than to serve indigenous tasks and pastimes.

(4) Social Resources, facilitating the community, institutional, and societal structures that support access to ICT. Are the settings such that young ICT learners are surrounded by people who support them in the ICT learning process, e.g., parents that help them with computers, to schoolmates that work on computer projects together, to village elders that value ICT in community life? Who are the intermediaries influencing ICT projects, such as public servants, NGOs, community-based organisations or private sector organisations? How are they helping adapt and shape ICTs, mediating or negotiating between the familiar and the new? Is the impact of the information society vision that drives policy initiatives in most developing 
countries limited to the minorities who find its global, symbolic and material value meaningful in their way of living and therefore are willing and able to acquire the skills and attitudes required to exploit its potential?

\section{Conclusions}

ICT in Africa is clearly at a very early stage. Rightly it is being driven by lofty visions of the potential of ICT to transform essentially agrarian economies into knowledge societies, visions of dramatically improving the learning conditions for millions of African students who cannot afford books, of a health system that can exploit international best practice to come to terms with rampaging diseases, and of enabling countless African entrepreneurs to enter the global marketplace. For many obvious reasons this process of transformation must take a long time. Indeed, given the history of Africa, political and technological progress on the continent has been quite impressive. It will be many years, though before the vision of an African Information Society is realised.

\section{APPENDIX}

The Acacia Initiative: www.idrc.org/acacia

The African Connection: www.africanconnection.org

The African Information Society Initiative: www.uneca.org/aisi

Building Digital Opportunities: www.dfid.org.uk

Francophonie Information Highway Fund: www.francophonie.org

IICD ICT Activities: www.iicd.org

ITU's Internet Training Initiative: www.itu.int

Leland Initiative: www.usaid.gov/leland

Regional Information Network for Africa:

www.unesco.org/webworld/informatics/rinaf.htm

UNDP Initiatives: www.undp.org

Digital Opportunity Task Force: www.dotforce.org

UN ICT Task Force: www.unicttaskforce.org

The French reader will take advantage of consulting: Enjeux des technologies de la communication en Afrique. Du téléphone à Internet, sous la dir. d'Annie Chéneau-Loquay, Paris, Khartala 2000, Coll. Regards. He will find inserted a CD-ROM 'Internet au Sud' edited par Pascal Renaud. (Note of the editor) 
Warschauer, M. Reconceptualizing the Digital Divide. First Monday Peerreviewed Journal on the Internet

2 www.infopol.gov.mz

3 The pre-paid model obviates the need for subscribers to take out long term contracts. Users acquire a mobile handset by whatever means and then purchase a SIM card plus a "starter kit" that includes a mobile number plus a number of "minutes." Thereafter they can recharge their phones with additional minutes as and when they choose, exercising direct control over their expenditures. It is estimated that well over $80 \%$ of mobile usage is based on this model.

4 Indeed recently the ITU proposed changing its definition of public access to telecom services from telecentres to cybercafés.

5 A well-known computer technicians' certification is $\mathrm{A}+$ (see www.comptia.org). The dominant international certification for basic user computing skills, covering word processing, spreadsheets, presentation graphics, data base usage and Internet usage is the International Computer Driving License (see www.ecdl.org)

6 www.balancingact-africa.com

7 Warschauer, M. op. cit. 